\title{
EXPERIMENTAL ANALYSIS OF ALUMINIUM ALLOY METAL MATRIX COMPOSITE WITH TUNGSTEN CARBIDE BY IN-SITU METHOD USING SEM
}

\author{
M. Rajaram Narayanan ${ }^{1 *}$ and S. Nallusamy ${ }^{2}$ \\ ${ }^{1,2}$ Department of Mechanical Engineering, \\ Dr. M G R Educational and Research Institute, Chennai-600095, Tamilnadu, India \\ *E-mail: drmrajaram@yahoo.com
}

\begin{abstract}
Aluminium matrix composites have more research focus due to its outstanding properties of specific strength, superior wear resistance and low thermal expansion. The main objective of this research is to estimate the effect of friction stir processing on microstructure and properties of aluminium alloy with tungsten carbide metal matrix insitu composite by low-cost stir casting technique. Friction stir processing is used to modify the cast microstructure of aluminium alloy 2024 with tungsten carbide metal matrix composite. The fabricated composite specimens were subjected to a series of mechanical and microstructural analysis. The observed results were compared with the results of base alloy material. Scanning electron microscope, optical microscopy and micro hardness test were carried out to analyze the microstructure and the dispersion of the reinforced particles in the composite alloy specimens. From the results it was found that, the mechanical properties like hardness value increases due to surface modification when compared with the base aluminium alloy.
\end{abstract}

Keywords: FSP, Aluminium Matrix Composite, Tungsten Carbide, Mechanical Properties, SEM.

(C) RASĀYAN. All rights reserved

\section{INTRODUCTION}

Aluminium matrix composites (AMCs) are now a day's extensively replacing conservative aluminium alloys in most of the components in aerospace, automobile and marine applications ${ }^{1-3}$. The research was done to enhance the various properties of AMCs using different novel processes and reinforcements are predictably produced by stir, squeeze and compo casting techniques ${ }^{4-6}$. Aluminium alloy 2024 and Tungsten carbide composite materials are prepared by a process called powder metallurgy. Stir casting technique is most suitable for producing metal matrix composites with $30 \%$ volume fractions of reinforcement $^{7-10}$. In stir casting process a major apprehension is the isolation of strengthening particles and the distribution of the particles in the molten matrix are depending on the different geometries of the particles added ${ }^{11-14}$. In stir casting technique there is a two-step mixing process where it is used in the fabrication of aluminium alloy composite ${ }^{15-17}$. An experimental analysis was done on different MMCs and it was found that metal cracks always prompted for the period of the matrix crossing points and also based on the bonding of the particle ${ }^{18-21}$. Similarly, Nano mixed materials and lubricants are used as fillers and nano agents in nanocomposites and nano fluids to change the different properties and heat transfer rates in different fields like mechanical, aeronautical, electrical and electronics ${ }^{22-25}$. Similarly, polymer reinforced nanocomposites with inorganic nanoparticles are much better due to their light weight, homogeneity, low cost and simple physical properties ${ }^{26-29}$.

Friction stir processing (FSP) is a technique to change the metal properties by concentrated plastic deformation confined to a small area as shown in Fig.-1. This deformation will be carried out by a unique method where frictional heat causes the metal to soften..$^{30-34}$. During this method, the material experiences with concentrated plastic deformation and these results in major refinement of grains ${ }^{35-38}$. FSP is changing the physical properties without a change in physical state of material to develop things such as high-strainrate superplasticity. The branches of processes on friction stir welding (FSW) is used to weld two different material work pieces jointly without changing the physical state of the material ${ }^{39-41}$. Based on the 
above study, in this research work AA2024 with tungsten carbide (WC) aluminium matrix composites are fabricated using in-situ casting method and the consequences on microstructure and properties by friction stir processing of AMCs were studied.

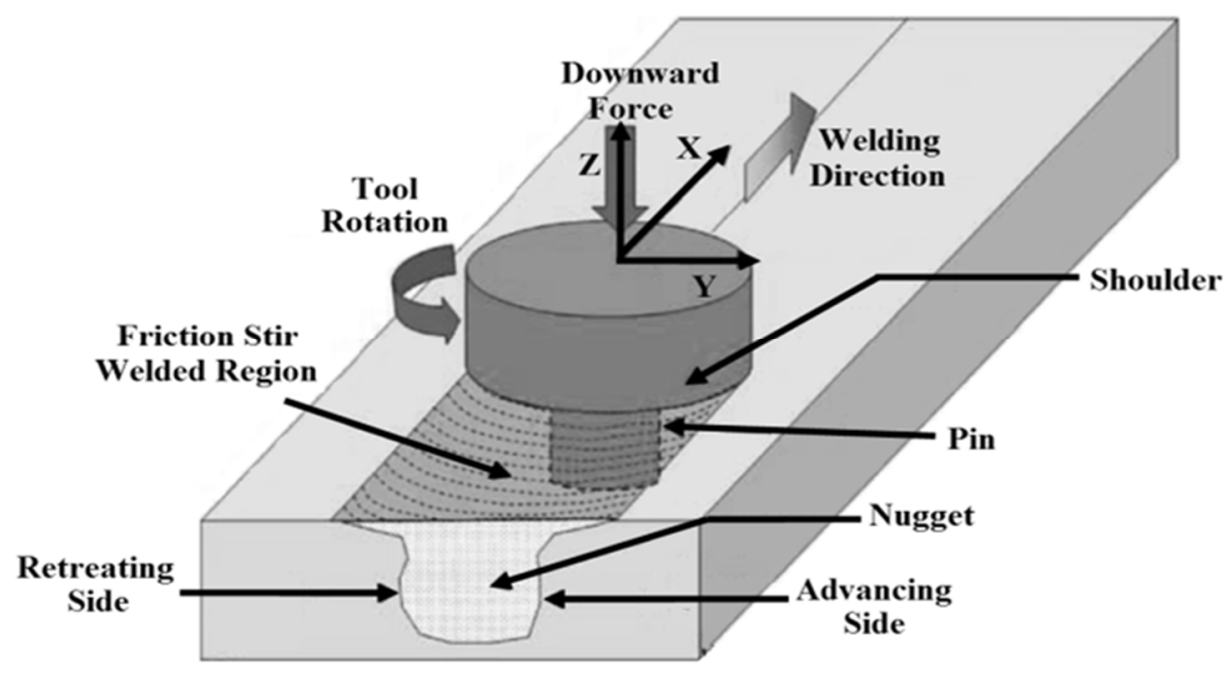

Fig.-1: Friction Stir Processing under FSW

\section{Sample Preparation}

\section{EXPERIMENTAL}

An Aluminium 2024 alloy plate, WC is the materials used primarily in the preparation of composites. High temperature with $900^{\circ} \mathrm{C}$ the muffle can help to melt the aluminium alloy very fast with minimizing the oxidation level and also enhances the wettability of the reinforcement particles. The preheated aluminium is melting at $638^{\circ} \mathrm{C}$ where the inert gas of nitrogen gas is used. WC with the weight of 200 grams dropped into the crucible after preheating at a temperature of $1000^{\circ} \mathrm{C}$ for about 20 minutes then the temperature reached to $760^{\circ} \mathrm{C}$. The temperature of the heater is set to $630^{\circ} \mathrm{C}$ for getting the uniform semisolid stage of the molten matrix. Reinforcements are poured manually with a flow rate of 0.5 grams per second and after stirring 5 minutes at semisolid stage slurry was reheated by holding about $900^{\circ} \mathrm{C}$. Polishing of the specimen was carried out with P220 grit ALO paper with water as a lubricant. The speed of the grinding wheel is 100/100 rpm and the time taken for grinding until the plane is one minute. Etching of the specimen was carried out with the etchant of Keller's reagent. Highlights features in aluminium and aluminium alloys and occasionally its more effective by showing grain boundaries mixed as $1.0 \mathrm{ml}$ hydrogen fluoride and $1.5 \mathrm{ml}$ hydrochloric acid in $2.5 \mathrm{ml}$ nitric acid with $95 \mathrm{ml}$ water. The tool specifications used in FSP is shown in Table-1.

Table-1: FSP Tool Specifications

\begin{tabular}{l|l}
\hline Material & AA 2024 \\
\hline Size of the Plate & $100 \times 100 \times 10(\mathrm{~mm})$ \\
\hline Reinforcement Particle & WC with $4-10 \mu \mathrm{m}$ \\
\hline Tool Material & EN 31 tool steel \\
\hline Heat Treatment & $\begin{array}{l}\text { Soaking period with } 800^{\circ} \mathrm{C} \text { about } 2.5 \text { hours. Quenching oil } \\
\text { tempering with } 100^{\circ} \mathrm{C} \text { about } 1 \text { hour. }\end{array}$ \\
\hline Rake Angle & 2.5 degree \\
\hline
\end{tabular}

\section{RESULTS AND DISCUSSION}

Microstructural characterization was carried out on metallographically polished samples to investigate morphological characteristics of grain and secondary phase. Inversed microscope analysis and scanning 
RASĀYAN J. Chem.

Vol. 11 | No. 1 |355 - 360 | January - March | 2018

electron microscope (SEM) analysis were conducted for both Al 2024 alloy and aluminium with the titanium carbide composite material.

\section{Optical Microscope Analysis}

Figure $2 \mathrm{~A}$ and $3 \mathrm{~A}$ shows irregular boundary structure and have interconnected and coarse grain structure. Clogged black smoky appearance is observed in stir cast MMCs shown in figure $2 \mathrm{~B}$ and $3 \mathrm{~B}$. From the optical microscope images, it was observed that stir casting leads to dispersion of tungsten carbide throughout the matrix. But the smoky appearance signifies the presence of agglomeration of reinforcement in the matrix. After FSP the refined microstructure of grains and grain boundaries indicate more even distribution of reinforcement in the matrix with enhanced microstructure is shown in figure 2Cand $3 \mathrm{C}$.

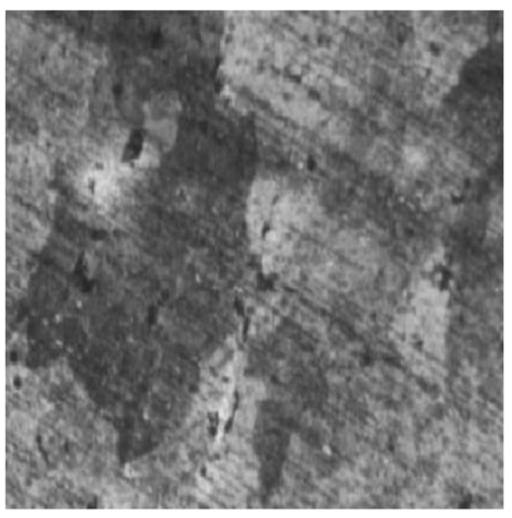

(A) $\mathrm{Al} 2024$

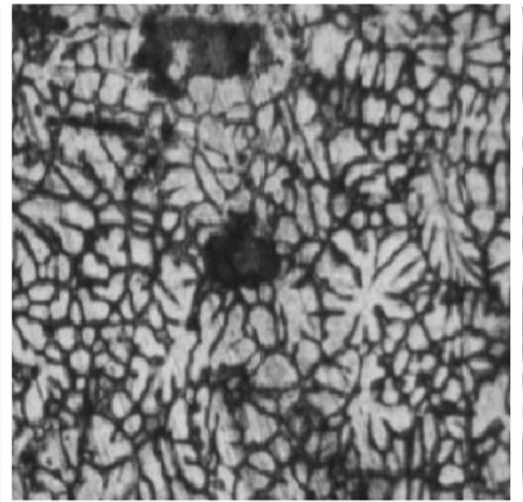

(B) MMC

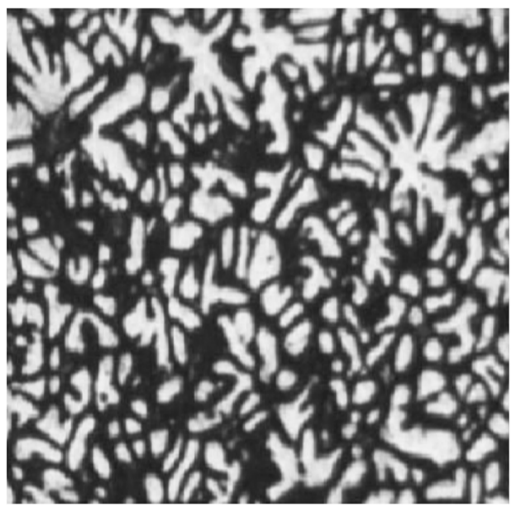

(C) MMC after FSP

Fig.-2: Microscopic Images under 100X Magnifications

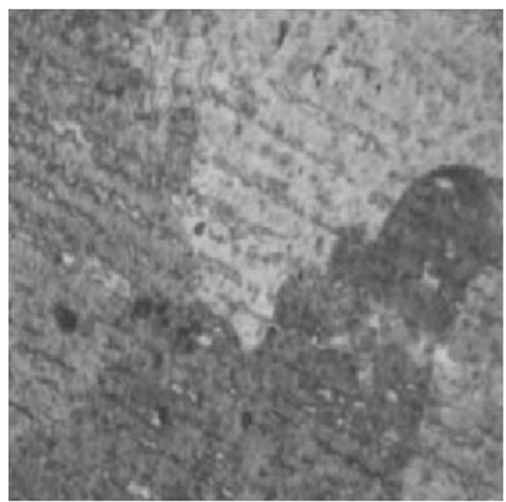

(A) $\mathrm{Al} 2024$

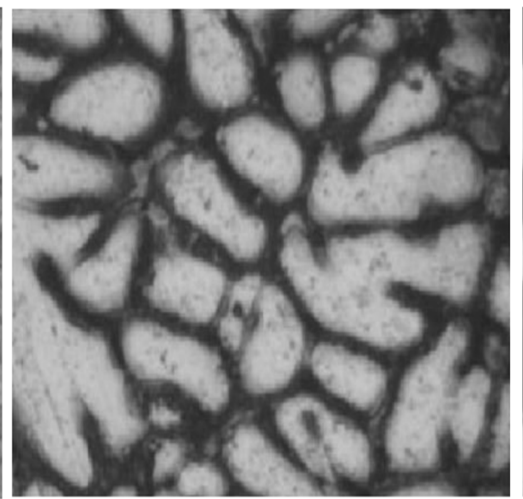

(B) $\mathrm{MMC}$

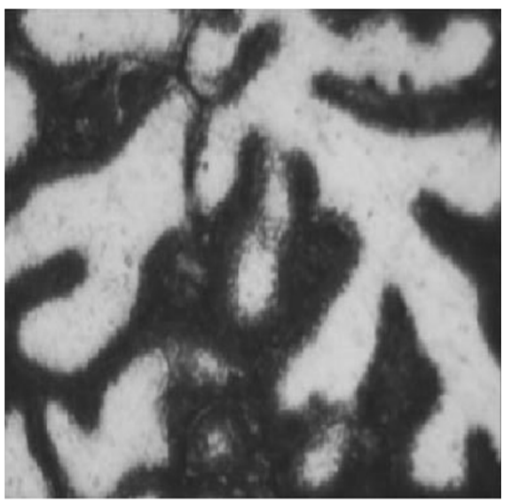

(C) MMC after FSP

Fig.-3: Microscopic Images under 400X Magnifications

\section{SEM Analysis}

Comparative SEM analysis of three samples was carried out. Fig.-4 and Fig.-5 show the SEM analysis images of aluminium 2024, stir cast AA2024 with WC material under 1000X and 2000X magnifications. AA 2024 shows irregular boundary structure and interconnected and coarse grain structure shown in figure 4A and 5A. Oxide layers, non refined grain structures are observed in casted MMC and are shown in figure $4 \mathrm{~B}$ and $5 \mathrm{~B}$ respectively. Reinforcement addition gives morphology changes of the phase from coarse unified dendrites to the microstructure of fine equiaxed with homogenous sharing of primary $\alpha$ phase. Broken dendrite structure is observed in MMC with a lot of debris like structures throughout the grain boundaries. 
RASĀYAN $J$. Chem.

Vol. 11 | No. 1 |355 - 360 | January - March | 2018

SEM images give a detailed and more clear explanation of the dispersion of reinforcement in the matrix and agglomeration at certain sites. After FSP the grain structures have expanded and are more refined as shown in figure 4C and 5C. SEM images give detailed and more clear explanation on dispersion of reinforcement in the matrix and agglomeration at certain sites before FSP. It can be inferred that reinforcement is distributed more even in the matrix after FSP which in turn enhance the physical property of MMC also.

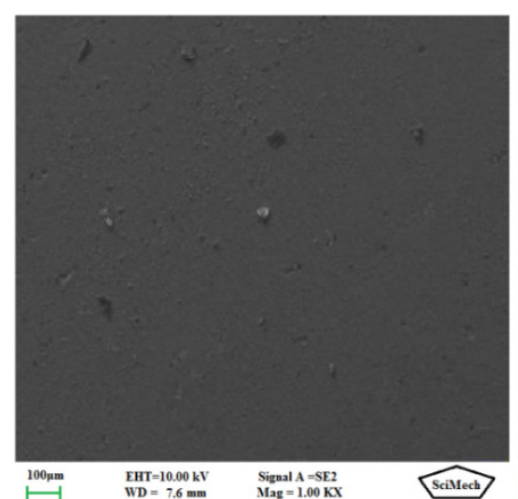

(A) $\mathrm{Al} 2024$

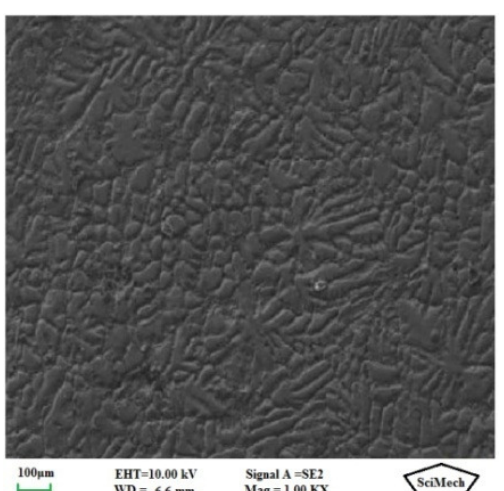

(B) MMC

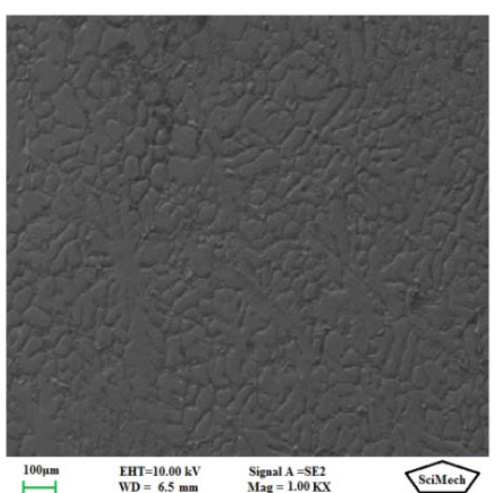

(C) MMC after FSP

Fig.-4: SEM Analysis under 1000X Magnifications

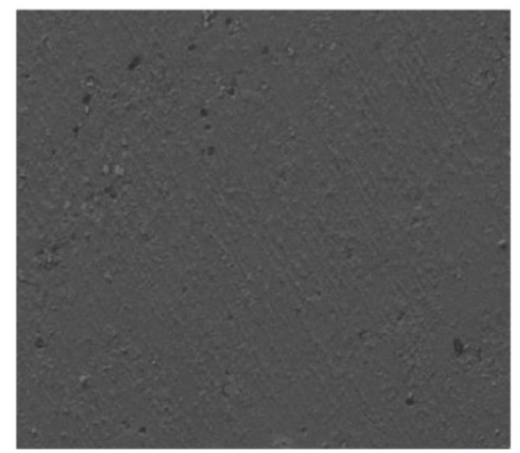

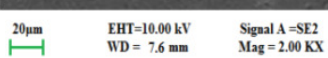

(A) $\mathrm{Al} 2024$

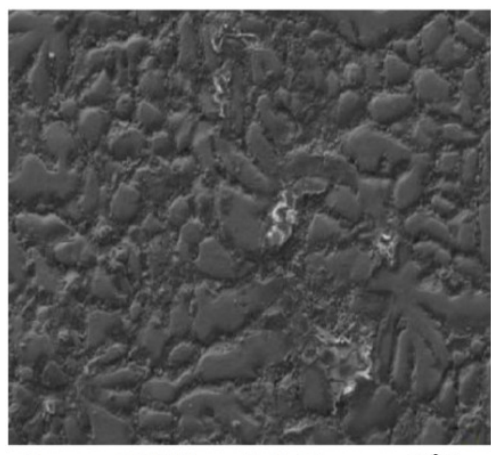

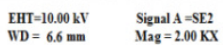

(B) MMC

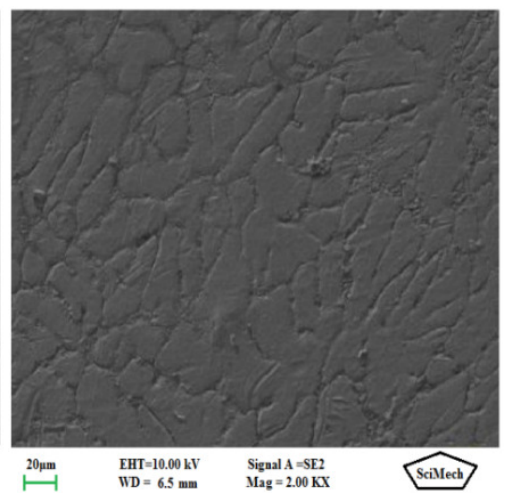

(C) MMC after FSP

Fig.5- SEM Analysis under 2000X Magnifications

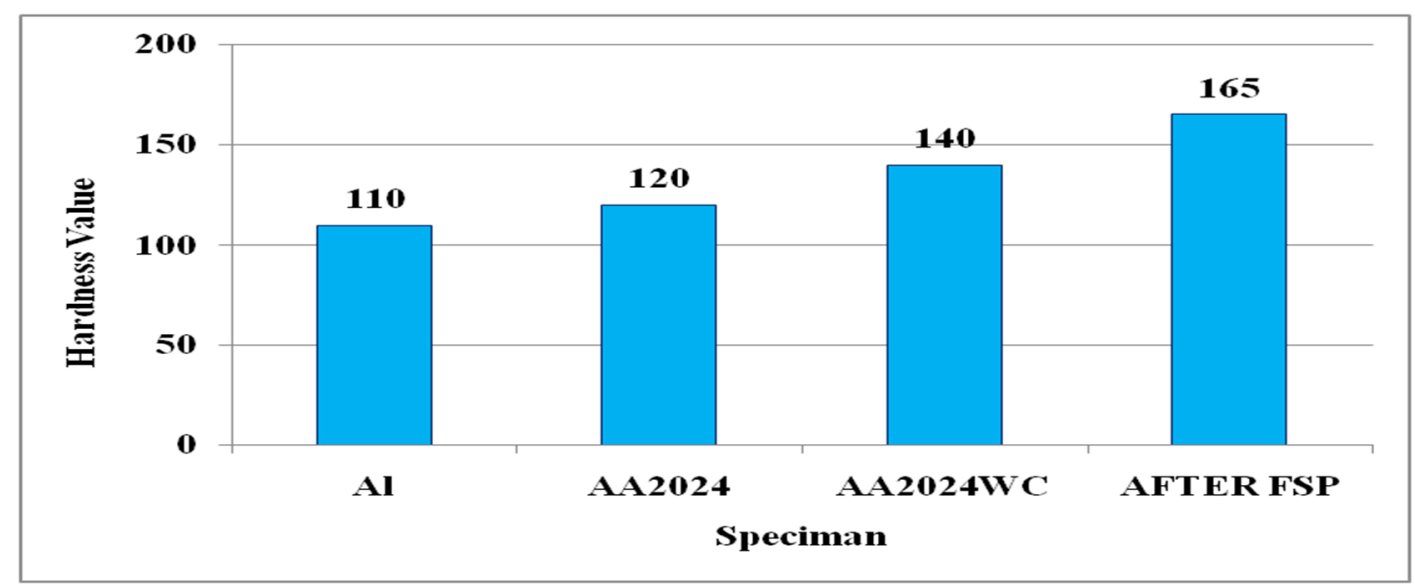

Fig.- 6: Micro Hardness Values of Different Specimens 


\section{RASĀYAN J. Chem.}

Vol. 11 | No. 1 | 355 - 360 | January - March | 2018

\section{Micro Hardness Analysis}

Average micro-hardness of pure aluminium, AA 2024, alumimium tungsten (Al-WC) MMC before FSP and Al-WC MMC after FSP were calculated and shown in figure 6. From the graph there is a progressive increase of hardness value. Micro-hardness has significantly increased which means there is a significant increase in the surface toughness of the aluminium alloy with the tungsten carbide metal matrix composite material.

\section{CONCLUSION}

Al-WC metal matrix composite was prepared with defect free and uniformly distributed up to a considerable depth by using the In-situ technique. The different analysis like optical microscopy, SEM analysis and micro hardness test were conducted. Based on the experimental results the following destinations appeared.

- Aluminum metal matrix composite was efficiently manufactured by In-situ Method and uniform distribution of ceramic particles along the material surface was achieved by friction stir processing.

- Friction stir processing is used as a tool to enhance the uniform distribution of particle along the surface of the matrix, which resulted in mechanical as well as micro structural modification.

- After FSP the refined microstructure of grains and grain boundaries signifies more even distribution of reinforcement in the matrix with enhanced microstructure

- From the SEM analysis, it was found that, the reinforcement is distributed more even in the matrix after FSP which in turn enhance the physical property of MMC.

- In the micro-hardness analysis, there is a significant increase was found in the surface toughness of the prepared composite material.

1. J. Singh, Friction, 4(14), 01 (2016)

2. S. Nallusamy and A. Karthikeyan, Indian Journal of Science and Technology, 9(35), 01 (2016)

3. I. Dukov Superheavy, Khimiya, 25, 596 (2016)

4. R. SuganthiniRekha, S. Nallusamy, R. Vijayakumar and S. Saravanan, International Journal of Applied Engineering Research, 10(62), 133 (2015)

5. Baradeswaran and Perumal, Composites: Part B, 56, 464 (2014)

6. A. Karthikeyan and S. Nallusamy, International Journal of Engineering Research in Africa, 31, 36 (2017)

7. S. Nallusamy, International Journal of Performability Engineering, 12(2), 143 (2016)

8. S. Kumar, Ravindranath and Shankar, Materials Science, 5, 908 (2014)

9. S. Nallusamy, Journal of Nano Research,40, 99 (2016)

10. C. Purnawan, Wahynningsihr and Aisyah, Khimiya, 26, 737 (2017)

11. S. Nallusamy, and Saurabh Kumar, Indian Journal of Science and Technology, 9(16), 01 (2016)

12. S. Jeevanantham, N.M. Sivaram, D.S. Robinson Smart, S. Nallusamy and N. Manikanda Prabu, International Journal of Applied Engineering Research, 12(11), 2963 (2017)

13. S. Nallusamy, Balakannan, Chakraborty and Gautam Majumdar, International Journal of Applied Engineering Research, 10(68), 843 (2015)

14. Thomas, Parameshwaran, Muthukrishnan and Aravindkumaran, Materials Science, 5, 1182 (2014)

15. S. Nallusamy, S. Saravanan, V. Kannarasu and M. Rajaram Narayanan, Rasayan Journal of Chemistry, 10(4), 1368 (2017)

16. S. Nallusamy, International Journal of Engineering Research in Africa, 22, 112 (2016)

17. Shin, Choi and Bae, Materials Science and Engineering: A, 607(23), 605 (2014)

18. S. Nallusamy, R. SuganthiniRekha and A. Karthikeyan, IOP Conference Series: Materials Science and Engineering, 225, 01 (2017)

19. S. Jeevanantham, David Rathnaraj, Robinson Smart, S. Nallusamy and N. Manikanda Prabu, Indian Journal of Science and Technology, 9(37), 01 (2016)

20. S. Nallusamy and A. Karthikeyan, Journal of Nano Research, 49, 01 (2017) 
RASĀYAN $J$. Chem.

Vol. 11 | No. 1 | 355 - 360 | January - March | 2018

21. S. Nallusamy, A. Manoj Babu and N. Manikanda Prabu, International Journal of Applied Engineering Research,10(62), 112 (2015)

22. Vereshchaka, Grigoriev and Sladkov, Applied Mechanics and Materials, 325-326, 1454 (2013)

23. S. Nallusamy, Manikanda Prabu, Balakannan, and Gautam Majumdar, International Journal of Engineering Research in Africa, 16, 17 (2015)

24. Vereshchaka, Sotova, Batako and Vereshchaka, Journal of Friction Wear, 35(6), 483 (2014)

25. S. Nallusamy and A. Manoj Babu, Journal of Nano Research, 37, 58 (2015)

26. S. Sendilvelan, K. Bhaskar and S. Nallusamy, Rasayan Journal of Chemistry, 10(2), 545 (2017)

27. S. Nallusamy, S. Sendilvelan, K. Bhaskar and N. Manikanda Prabu, Rasayan Journal of Chemistry, 10(3), 873 (2017)

28. C.H. Lai, K.H. Cheng, Lin and Yeh, Surface and Coatings Technology, 202(15), 3732 (2008)

29. S. Nallusamy and J. Logeshwaran, Rasayan Journal of Chemistry, 10(3), 1050 (2017)

30. S. Nallusamy, Journal of Nano Research, 40, 105 (2016)

31. S. Nallusamy and Manikanda Prabu, International Journal of Nanoscience, 16(5\&6), 01 (2017)

32. S. Nallusamy, Pollution Research, 34(4), 721 (2015)

33. S. Nallusamy, Journal of Nano Research, 45, 155 (2017)

34. K. Kanthavel, Sumesh and Saravanakumar, Alexandria Engineering Journal, 55(1), 13 (2016)

35. S. Nallusamy, M. Rajaram Narayanan and S. Hariharan, Rasayan Journal of Chemistry, 10(4), 1289 (2017)

36. S. Omar, Hengan Ou, Sun and D.G. McCartney, Materials and Design, 86, 61 (2015)

37. S. Nallusamy and Gautam Majumdar, International Journal of Performability Engineering, 12(3), 229 (2016)

38. Sergey N. Grigoriev and Alexey A. Krapostin, Mechanics and Industry, 17(7), 01 (2016)

39. S. Nallusamy, Manoj Babu and M.K. Prabu, International Journal of Applied Engineering Research, 10(62), 112 (2015)

40. S. Nallusamy, Journal of Nano Research, 50, 105 (2017)

41. S. Nallusamy, International Journal of Engineering Research in Africa, 21, 110 (2016)

[RJC-2047/2017] 